\title{
General Anesthesia
}

\section{Intravenous fluid loading with or without supple- mentary dextrose does not prevent nausea, vomit- ing and pain after laparoscopy}

\section{[Une charge liquidienne avec ou sans dextrose supplémentaire ne prévient pas les} nausées, les vomissements et la douleur après une laparoscopie]

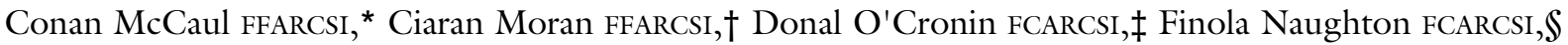
Michael Geary MD, II Edmund Carton FFARCSI, ${ }^{*}$ James Gardiner FFARCSI*

Purpose: To examine the effects of iv compound sodium lactate (CSL) with and without caloric supplementation with dextrose on nausea, vomiting and pain following general anesthesia for laparoscopy.

Methods: We compared iv fluid loading with and without supplementary dextrose for the prevention of postoperative nausea and vomiting (PONV). In a prospective double-blinded controlled trial, 120 ASA I female patients undergoing elective gynecological laparoscopy were randomized to one of three groups, and received either: (a) CSL $1.5 \mathrm{~mL} \cdot \mathrm{kg}^{-1}$ per hour fasting duration; (b) CSL, I.5 $\mathrm{mL} \cdot \mathrm{kg}^{-1}$ per hour fasting duration with $0.5 \mathrm{~g} \cdot \mathrm{kg}^{-1}$ dextrose added in $50 \%$ formulation (CSL/dextrose); or (c) no iv fluid (control).

Results: Compared with control the percentage of patients who had no PONV within $24 \mathrm{hr}$ of anesthesia in the CSL and CSL/dextrose groups was $78 \%$ vs $83 \%$ and $71 \%, P=0.81$ and $P=0.683$ respectively. The numbers needed-to-harm for causing PONV episodes in CSL/dextrose vs CSL or control groups were 5.7 [95\% confidence interval (Cl), 5.57-5.9l] and 8.2 (95\% Cl, 8.0 I-8.37) respectively. The number needed-to-treat for prevention of PONV episodes in CSL vs control was 19.2 (95\% Cl, 19.08-19.37). A greater proportion of patients in the $\mathrm{CSL} /$ dextrose group required narcotic analgesia in the postanesthetic care unit compared to those in the control group (16/35 vs 7/37, $P=0.03$ ). The CSL/dextrose group also demonstrated hyperglycemia (serum glucose $14.0 \pm$ 3.94 vs $5.0 \pm 1.01$ vs $5.2 \pm 0.9 \mathrm{mmol} \cdot \mathrm{L}^{-1}, P<0.000 \mathrm{I}$ ) in the postanesthetic care unit compared to the CSL and control groups. The CSL/dextrose group also reported increased thirst at $24 \mathrm{hr}$ compared to control (20/35 vs II/37, $P=0.035)$.
Conclusion: These findings suggest that: I) administration of dextrose is associated with nausea, increased opioid requirement and late thirst after elective gynecological laparoscopy; 2) iv fluids did not decrease PONV.

Objectif: Vérifier les effets d'un lactate de sodium composé iv (LSC), avec et sans apport calorique complémentaire avec du dextrose, sur les nausées, les vomissements et la douleur après une anesthésie générale pour laparoscopie.

Méthode : Nous avons comparé une charge liquidienne avec et sans dextrose supplémentaire comme prévention des nausées et vomissements postopératoires (NVPO). Une étude prospective, contrôlée et à double insu a été réalisée auprès de 120 femmes d'état physique ASA I devant subir une laparoscopie gynécologique réglée. Les patientes, réparties en trois groupes, ont reçu: (a) $1,5 \mathrm{~mL} \cdot \mathrm{kg}^{-1}$ de $L S C$ par heure de jeûne ; (b) $1,5 \mathrm{~mL} \cdot \mathrm{kg}^{-1}$ de LSC par heure de jeûne avec $0,5 \mathrm{~g} \cdot \mathrm{kg}^{-1}$ de dextrose ajouté dans une préparation à $50 \%$ (LSC/dextrose) ou (c) aucun soluté (témoin).

Résultats : Comparé à celui des témoins, le pourcentage de patientes sans NVPO pendant les 24 h qui ont suivi l'anesthésie dans les groupes LSC et LSC/dextrose a été respectivement de $78 \%$ vs $83 \%$ et $71 \%$, $P=0,8$ l et $P=0,683$. Le nombre de patientes lésées, nécessaire pour causer des NVPO dans le groupe LSC/dextrose vs les groupes LSC ou témoin a été respectivement de 5,7 [intervalle de confiance de $95 \%$ (IC), 5,57-5,9I] et 8,2 (IC de $95 \%, 8,01-8,37$ ). Le nombre néces-

From the Departments of Anaesthesia* and Obstetrics and Gynaecology, Rotunda Hospital, Dublin, Ireland; Anaesthesia, $†$ The Robert Jones Agnes Hunt Orthopedic Hospital, Oswestry, United Kingdom; Anaesthesia,‡ Cork University Hospital, Cork, Ireland; Anaesthesia, $\$$ Beaumont Hospital, Dublin, Ireland.

Address correspondence to: Dr. Conan McCaul, Departments of Anaesthesia and Critical Care Medicine, Hospital for Sick Children, 555 University Avenue, Toronto, Ontario M5G 1X8, Canada. Phone: 416-813-7445; Fax: 416-813-7543; E-mail: conan.mccaul@utoronto.ca This study was presented in part, to the Postgraduate Assembly of Anaesthesia, New York, USA, in December 2000.

Accepted for publication August 12, 2002.

Revision accepted February 12, 2003. 
saire à traiter pour prévenir les NVPO dans le groupe LSC vs le groupe témoin a été de 19,2 (IC de $95 \%$, 19,08-19,37). Plus de patientes du groupe $\mathrm{LSC} /$ dextrose ont eu besoin d'analgésique narcotique en salle de réveil, comparées aux patientes témoins ( $16 / 35$ vs 7/37, $P=0,03$ ). À la salle de réveil, on a aussi trouvé de l'hyperglycémie dans le groupe LSC/dextrose (glucose sérique de 14,0 $\pm 3,94$ vs 5,0 $\pm 1,01$ vs $5,2 \pm$ $0,9 \mathrm{mmol} \cdot \mathrm{L}^{-1}, P<0,000 \mathrm{I}$ ), comparé aux groupes $\mathrm{LSC}$ et témoin. À 24 $h$, le groupe LSC/dextrose, comparé aux témoins, a aussi présenté une augmentation de la soif, (20/35 vs / //37, $P=0,035)$.

Conclusion : Ces résultats suggèrent que : I) l'administration de dextrose est associée aux nausées, à des besoins accrus d'opioïde et une soif tardive à la suite d'une laparoscopie gynécologique ; 2) les liquides iv ne diminuent pas les NVPO.

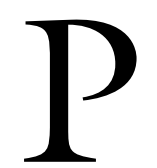

OSTOPERATIVE nausea and vomiting (PONV) remains one of the most common postoperative complications, ${ }^{1}$ causing discomfort, patient dissatisfaction, delayed discharge and increased costs.

We examined the hypothesis that: (a) supplementary dextrose would reduce the incidence of PONV, and (b) administration of balanced salt solution would also reduce such symptoms.

\section{Methods}

Following ethical approval and informed consent female patients undergoing elective diagnostic laparoscopy were recruited. Patients were subsequently excluded if they developed excessive blood loss or if the surgery progressed to additional procedures. Patients were randomized drawing unmarked envelopes containing assignment information and were blinded to their group allocation. The fluid volume to be administered was calculated on the basis of the interval since last oral intake $\left(1.5 \mathrm{~mL} \cdot \mathrm{kg}^{-1} \cdot \mathrm{hr}^{-1}\right.$ fasting time). ${ }^{2}$ The control group received no perioperative iv fluids; group compound sodium lactate (CSL)/dextrose received CSL with dextrose $0.5 \mathrm{~g} \cdot \mathrm{kg}^{-1}$ added to the infused solution as a $50 \%$ formulation; group CSL received compound sodium lactate alone. CSL contains $\mathrm{Na}^{+} 131, \mathrm{~K}^{+} 5, \mathrm{Ca}^{2+} 2, \mathrm{Cl}-111$, lactate 29 $\mathrm{mmol} \cdot \mathrm{L}^{-1}, \mathrm{pH}$ 6.5. Fluid was administered following induction of anesthesia over approximately $20 \mathrm{~min}$. Standardized general anesthesia was administered (Table I). The lungs were mechanically ventilated and anesthesia was maintained with sevoflurane in $\mathrm{O}_{2} / \mathrm{N}_{2} \mathrm{O}$ in a $1: 2$ ratio. All patients received neostigmine/glycopyrrolate, rectal diclofenac and wound infiltration with bupivacaine. Pharmacological antiemetic prophylaxis was not given. Standardized antiemetic and analgesic rescue medications were avail- able. Patients were assessed by a blinded interviewer using a standardized questionnaire in the postanesthesia care unit (PACU), two hours later in the ward; and on the first postoperative morning. An adverse outcome was defined as the occurrence nausea, vomiting, antiemetic use, thirst, dizziness or sore throat.

\section{Sample size estimation}

Projecting an incidence of $70 \%$ in controls and a $50 \%$ reduction with treatment we estimated 31 patients per group, $(\alpha=0.05, \beta=0.8)$. To allow for dropouts we randomized a total of 120 patients.

\section{Statistical analysis}

Statistics were performed using Sigma Stat ${ }^{\complement}$, (version 2.0 Jandel Scientific, Chicago, IL, USA). $P<0.05$ was considered significant. ANOVA, Student's t test and Chi-square were used as appropriate. Quantitative analyses of effect was assessed by calculation of the numbers needed-to-treat (NNT), numbers neededto-harm (NNH) and 95\% confidence intervals (CI).

\section{Results}

After exclusions, data from 108 patients were analyzed. On hypothesis testing there was no statistically significant difference in PONV episodes between groups. Compared with control the percentage of patients who had no PONV within $24 \mathrm{hr}$ of anesthesia in the CSL and CSL/dextrose was $78 \%$ vs $83 \%$ and $71 \%, P=0.81$, $\chi^{2}$ and $P=0.683, \chi^{2}$ respectively. The $\mathrm{NNH}$ for PONV episodes in CSL/dextrose vs CSL or control were 5.7 (95\% CI, 5.57-5.91) and 8.2 (95\% CI, 8.01-8.37) respectively. The NNT for PONV episodes in CSL vs control was 19.2 (95\% CI, 19.08-19.37). The CSL/dextrose group was more hyperglycemic than control or CSL groups $\left(P<0.0001, \chi^{2}\right)$ in the PACU. More CSL/dextrose patients received fentanyl in the PACU than the control group $(46.7 \%$ vs $8.9 \%, P=$ $\left.0.03, \chi^{2}\right)$. Thirst was increased in the CSL/dextrose group at $24 \mathrm{hr}$ compared to control $\left(P=0.035, \chi^{2}\right)$.

\section{Discussion}

Perioperative rehydration and caloric supplementation may reduce $\mathrm{PONV}^{3}$ but important methodological issues confound previous studies. The present study aimed to retest these hypotheses in a group considered at high risk of PONV. We were unable to prove that administration of CSL or CSL with dextrose decreases PONV. Our study shows that administration of CSL/dextrose is associated with PONV in $17.5 \%$ of patients and with early hyperglycemia and late thirst. The NNT for PONV in patients receiving CSL was 19.2 suggesting that clinical benefit if any, is small. 
TABLE I Patient characteristics and medication

\begin{tabular}{llll}
\hline Groups & $\begin{array}{l}\text { Control } \\
n=37\end{array}$ & $\begin{array}{l}\text { CSL } \\
n=36\end{array}$ & $\begin{array}{l}\text { CSL } \\
n=35\end{array}$ \\
\hline Age $(\mathrm{yr})$ & $33.0 \pm 5.1$ & $32.3 \pm 4.96$ & $33.2 \pm 4.9$ \\
Weight $(\mathrm{kg})$ & $63.6 \pm 15.6$ & $62.0 \pm 9.3$ & $64.2 \pm 9.7$ \\
Fasting time $(\mathrm{hr})$ & $11.4 \pm 2.3$ & $11.63 \pm 2.36$ & $11.65 \pm 1.5$ \\
CSL volume $(\mathrm{mL})$ & 0 & $1,115 \pm 363 \ddagger$ & $1,148 \pm 210 \ddagger$ \\
Dextrose $(\mathrm{g})$ & 0 & 0 & $32 \pm 5.8 \ddagger$ \\
Duration of anesthesia $(\mathrm{min})$ & $23 \pm 7$ & $22 \pm 6$ & $23 \pm 7$ \\
Fentanyl: PACU $(n)$ & $7 / 37(18.9 \%)$ & $9 / 36(25 \%)$ & $16 / 35 \dagger(46.7 \%)$ \\
\hline
\end{tabular}

Categorical variables are presented as number and proportion, continuous variables are presented as mean and standard deviation. $\mathrm{CSL}^{*}=$ compound sodium lactate; PACU $=$ postanesthesia care unit. $\dagger P=0.03(\mathrm{CSL} /$ dextrose $v s$ control $) ; \ddagger P<0.0001,(\mathrm{CSL} / \mathrm{dextrose}$ and $\mathrm{CSL}$ ps control).

TABLE II Symptoms and therapy

$\begin{array}{lll}\text { Control } & \text { CSL } & \text { CSL/dextrose } \\ n=37 & n=36 & n=35\end{array}$

\section{PACU}

Patients reporting

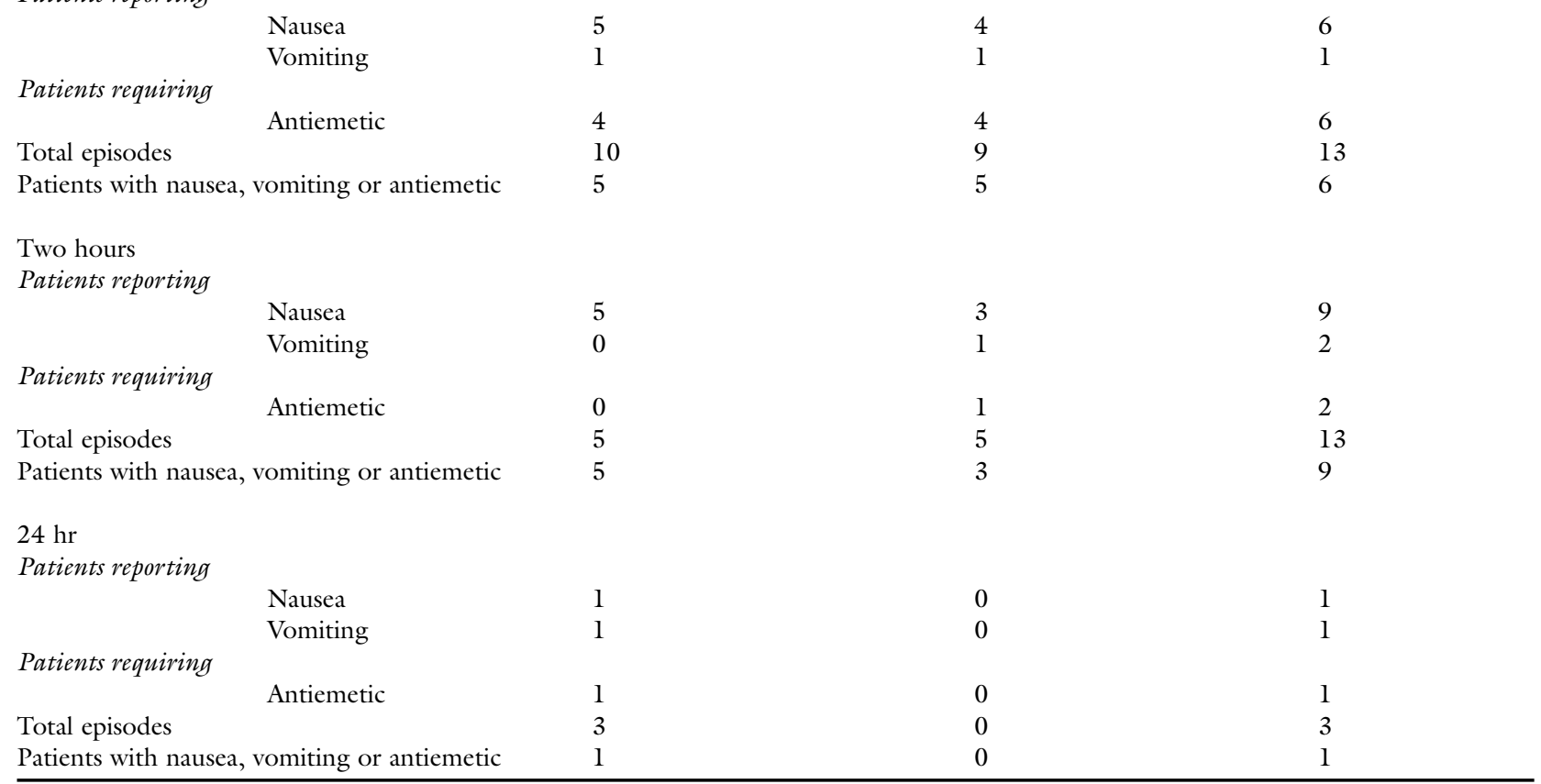

$\mathrm{CSL}=$ compound sodium lactate PACU = postanesthesia care unit.

Differences exist between our study and those of previous investigators. Yogendran et al. did not allow for fasting duration and the anesthetic technique had important confounding variability. ${ }^{4}$ Reduced dizziness, headache and sore throat were demonstrated by Cook et al. ${ }^{3}$ in patients given dextrose. The higher incidence of nausea in our study in the CSL/dextrose group (NNH 5.7) may be explained by our earlier patient assessment. The immediate postoperative period was associated with hyperglycemia in our patients in the CSL/dextrose group. Hyperglycemia is known to reduce gastric emptying and increase sensation of gastric fullness ${ }^{5}$ and is associated with adverse neurological ${ }^{6}$ cardiovascular $^{7}$ gastrointestinal ${ }^{5}$ and immunological ${ }^{8}$ effects. The previously demonstrated small benefit in subjective postoperative recovery symptoms may be insufficient to justify administration of solutions that cause hyperglycemia.

Opioids may reduce postoperative nausea by reducing pain, indicating a complex interaction between nociception, emesis and analgesia. The relationship between dextrose administration and pain has not to 


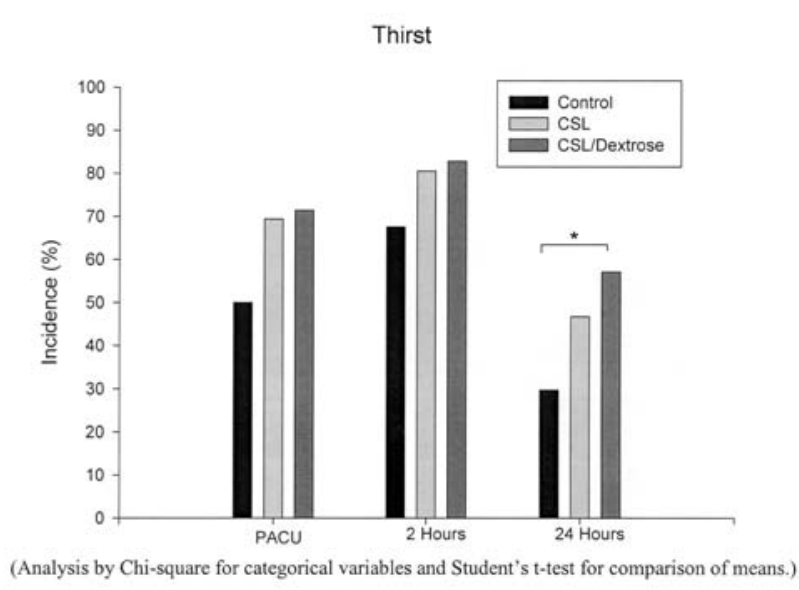

FIGURE Thirst. ${ }^{*} P=0.035$.

our knowledge been previously described. Glucose loading has been shown to elevate plasma cholecystokinin ${ }^{9}$ which is involved in modulating pain and altering acute tolerance to opiates. ${ }^{10}$ In our study, fentanyl administration in the PACU was more frequent in the CSL/dextrose than control indicating a possible relationship between hyperglycemia and opioid tolerance. Because acute hyperglycemia is also associated with increased sensitivity to gastric distension, ${ }^{5}$ the observed increase in fentanyl consumption in the CSL/dextrose group may indicate a hyperglycemia mediated increase in sensitivity to autonomic components of visceral nociception.

This study has potential limitations. First, this data may not be generalizable to different patient populations, lengthier or different surgical procedures, anesthetic techniques or all formulations of dextrose containing fluids. Second, individualized fluid therapy calculated to replace the deficit incurred by fasting may be impractical. Finally, the secondary hypothesis that $i v$ fluids would reduce the incidence of PONV was not proved. However, it was not disproved, and here the issue of sample size is important. The a priori sample size estimates proved adequate to test the primary hypothesis. Post hoc sample size calculation $(\alpha$ $0.05, \beta 0.80$ ) indicates that with nausea as low as reported in the current study over 600 patients per group would be required to demonstrate that iv fluid significantly decreases nausea. Expressed as NNT, this calculates as 19.2 patients treated for a single patient to benefit, which is far less than that of conventional antiemetics, suggesting that such treatment would have limited clinical usefulness.

\section{Conclusion}

The administration of either CSL or CSL with dextrose failed to significantly reduce PONV dizziness and sore throat compared to control. Dextrose administration resulted in hyperglycemia, increased analgesia requirement and late thirst. NNT and $\mathrm{NNH}$ analyses suggest that dextrose administration is associated with nausea whilst administration of CSL is associated with only a small clinical benefit. Further studies are needed to evaluate the finding of increased analgesic requirements and dextrose administration.

\section{Acknowledgements}

The authors would like to thank Dr. John Laffey for statistical advice and Dr. Brian Kavanagh for reviewing the manuscript.

\section{References}

1 Cholwill JM, Wright W, Hobbs GJ, Curran J. Comparison of ondansetron and cyclizine for prevention of nausea and vomiting after day-case gynaecological laparoscopy. Br J Anaesth 1999; 83: 611-4.

2 Aitkenhead A, Smith G. Appendix VIb: intraoperative fluid requirements - adult. In: Smith G, Aitkenhead $A R$. Textbook of Anaesthesia, 3rd ed. London: Churchill Livingstone; 1996: 748.

3 Cook R, Anderson S, Riseborough M, Blogg CE. Intravenous fluid load and recovery. A double-blind comparison in gynaecological patients who had daycase laparoscopy. Anaesthesia 1990; 45: 826-30.

4 Yogendran S, Asokumar B, Cheng DC, Chung F. A prospective randomized double-blinded study of the effect of intravenous fluid therapy on adverse outcomes on outpatient surgery. Anesth Analg 1995; 80: 682-6.

5 Hebbard GS, Sun WM, Dent J, Horowitz M. Hyperglycaemia affects proximal gastric motor and sensory function in normal subjects. Eur J Gastroenterol Hepatol 1996; 8: 211-7.

6 Pulsinelli WA, Levy DE, Sigsbee B, Scherer P, Plum F. Increased damage after ischemic stroke in patients with hyperglycemia with or without established diabetes mellitus. Am J Med 1983; 74: 540-4.

7 Marfella R, Nappo F, De Angelis L, Siniscalchi M, Rossi $F$, Giugliano D. The effect of acute hyperglycaemia on QTc duration in healthy man. Diabetologia 2000; 43: 571-5.

8 Marfella R, Esposito K, Giunta R, et al. Circulating adhesion molecules in humans. Role of hyperglycemia and hyperinsulinemia. Circulation 2000; 101: 2247-51.

9 Hasegawa H, Shirohara H, Okabayashi $\Upsilon$, et al. Oral glucose ingestion stimulates cholecystokinin release in normal subjects and patients with non-insulin-dependent diabetes mellitus. Metabolism 1996; 45: 196-202. 
10 Kissin I, Bright CA, Bradley EL Jr. Acute tolerance to continuously infused alfentanil: the role of cholecystokinin and N-methyl-D-aspartate-nitric oxide systems. Anesth Analg 2000; 91: 110-6.

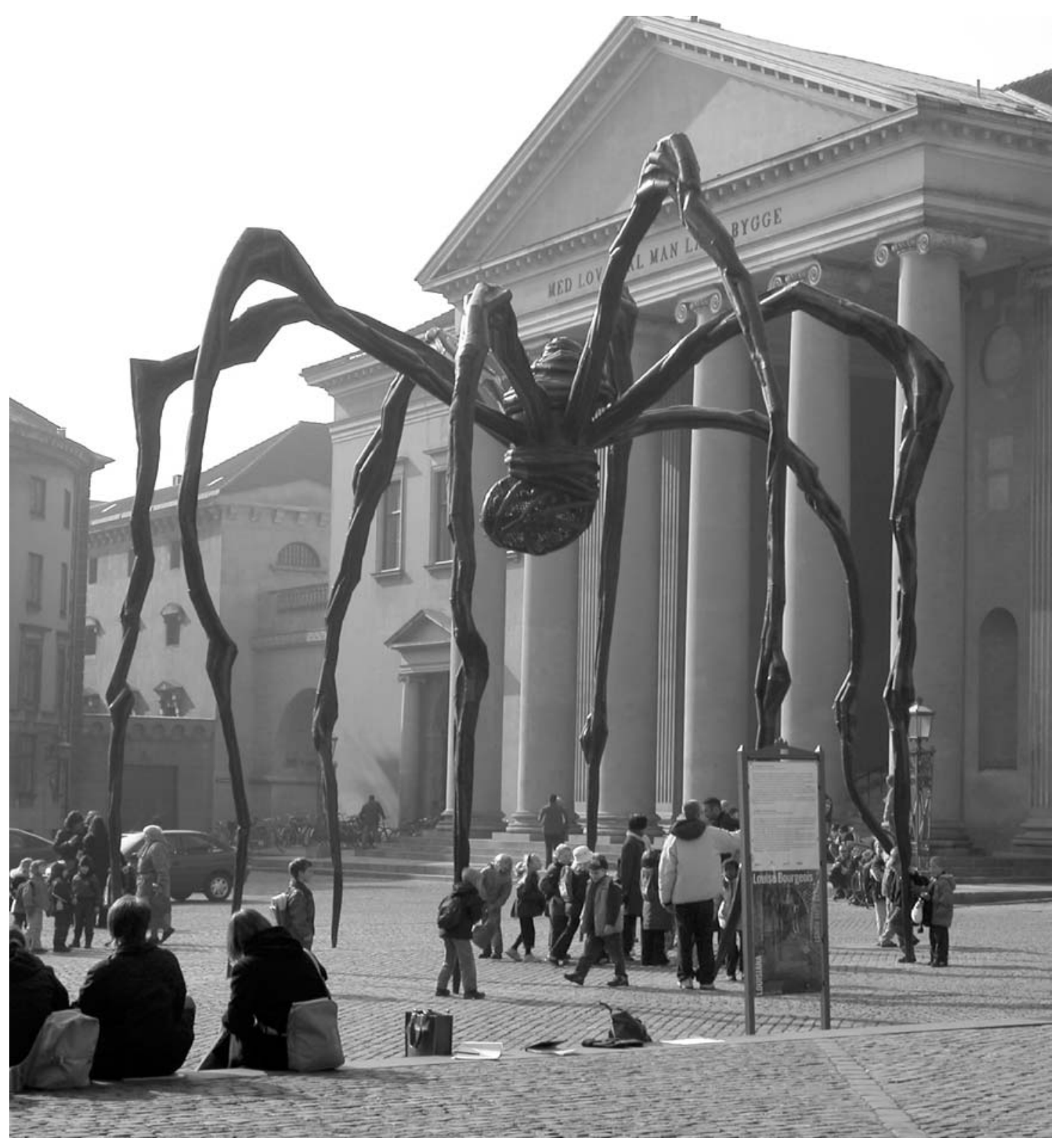

Sculpture ("Mother") exposed in Copenhagen 